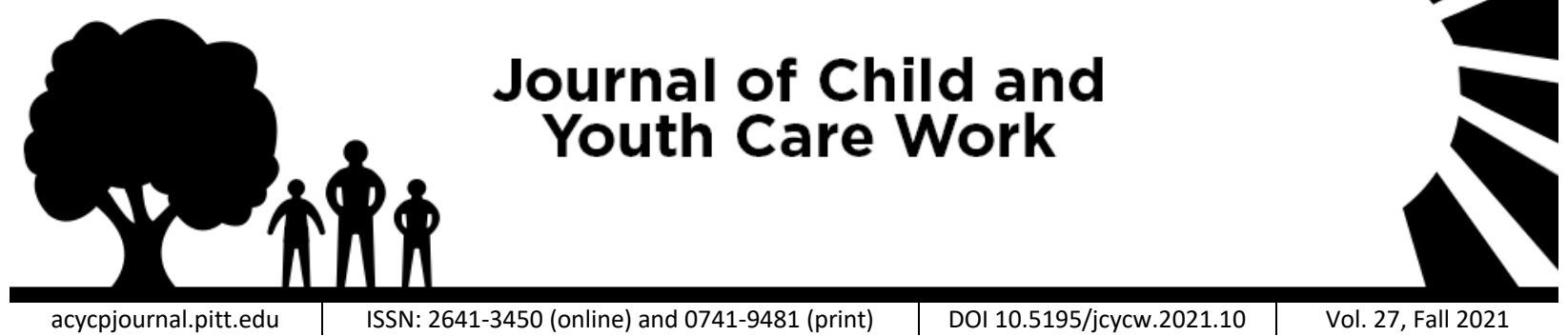

\title{
Cultivating Positive Youth Development through Latin American Street Soccer Programming
}

\author{
Caroline M. Petrilla, Diana Matteson, Dorienne J. Silva, Seamus Mannion and \\ Stacy L. Huggins \\ Youth Advocate Programs, Inc.
}

\begin{abstract}
Youth disconnected from their families and communities lack critical community supports, placing them at higher risk of establishing unhealthy behaviors that can lead to poor outcomes, including involvement in juvenile justice systems. They need assistance to develop essential life skills and family and community connections. Engaging youth and families, otherwise marginalized by society, in innovative, affordable, and effective ways is a global challenge. This paper summarizes the history of the Latin American launched global street soccer movement to promote inclusion and positive development of youth living in vulnerable situations. It explores the power and potential of street soccer's holistic and inclusive programming approach as a vehicle for individual transformation and community engagement. And it examines the evolving integration of the Latin American street soccer methodology in working with youth and families with complex needs, particularly as experienced by the nonprofit service organization Youth Advocate Programs, Inc. (YAP).
\end{abstract}

Keywords: Street Soccer, Positive Youth Development, PYD, Youth Advocate Programs, YAP, Mediation

Street soccer is gaining attention worldwide as a promising tool to engage youth and create social networks, particularly in developing countries (Kuntz, 2006). It involves a collective of organizations around the world that uses soccer to promote the inclusion and development of children and youth living in vulnerable situations (Youth Advocate Programs, Inc., 2021a,b). This paper explores the potential benefits of street soccer participation, particularly for youth with complex needs and challenges, through emphasizing the methodology at the center of the Latin American borne model with its core values of collaboration, respect and solidarity (Youth Advocate Programs, Inc. 2021a). It also shares the experience of Youth Advocate Programs, Inc. (YAP), an international nonprofit organization, in creating innovative national and international street soccer collaborations that foster 
opportunities for youth in environments of disadvantage to develop their potential as contributing community members.

Though research on the Latin American street soccer model specifically is just evolving, the overall benefits of street soccer are presented and analyzed herein through the lens of transformation. Studies and information relating to sports engagement and Positive Youth Development (PYD) are presented. PYD includes developing personal and social assets rather than focusing on deficits (Lerner, Lerner, et al., 2005). There is literature supporting personal and social PYD benefits of sports engagement, particularly when youth participate in holistic sports programs. The holistic view emphasizes a broader view of sports engagement beyond winning and athletic skills (Camp \& Gray, 2016). It views "healthy sport participation as resulting in positive social, physical, and mental experiences" (Camp \& Gray, 2016, p.2). Though there is a need for further youth sport research (AndersonButcher, 2019), youth participating in sports and physical activities are afforded pro-social opportunities to build character and critical life skills including conflict resolution and leadership (Fraser-Thomas, Côté \& Deakin, 2005), improvement of their physical and emotional wellbeing (US Department of Health and Human Services 2008; Fraser-Thomas et al., 2005), and community connectivity (Fundacion FUDE, 2021a,b,c). Sport-based youth development (SBYD) particularly references holistic and empowerment-based programs that prioritize the development of personal and social skills that are transferable to settings beyond sports (Hemphill, Janke, Gordon \& Farrar, 2018; Holt et al., 2017).

This paper explores the gap in literature as to the benefits and potential of the Latin American street soccer movement. It begins with an historical perspective, portraying the journey associated with channeling the benefits of the youth-directed free play of street soccer, where children take charge of games, learning and fun (Snow, 2011). It traces the history of Latin American Street Soccer from its modest origins in Argentina and other Latin American countries to the world stage. Then, attention is devoted to the components of the Latin American borne approach as a social innovation and gender equity model through addressing each step within the methodology and its specific purpose (Movimiento de Futbol Callejero, 2017a). Its potential as a PYD tool is subsequently explored. Finally, the paper shares YAP's historical journey and continued efforts to raise awareness and champion street soccer as a holistic approach to PYD and social transformation.

The authors declare their shared bias that recognition and integration of the Latin American Street Soccer methodology as an engaging, effective and low-overhead Positive Youth Development tool for youth with complex needs in challenged neighborhoods, offers hope for positive youth and community transformations.

\section{The Latin American Street Soccer Model}

While organized sport has the potential to play a significant role in contributing to positive youth development, it is necessary to recognize that development through sport is not automatic (Bailey, 2006; Fraser-Thomas et al., 2005). It is dependent upon a multitude of factors that must be considered when planning and designing youth sport programs (Fraser-Thomas et al., 2005). Putting together an effective youth sports program as a free-standing or complementary PYD initiative must be done mindfully. It is possible for sports' participation to have unintended, yet injurious, psychosocial impacts on youth participants. Some research ties negative emotional and psychological outcomes to participation in sports. Physical activity programs that emphasize interpersonal comparison can especially lead to negative outcomes (Ullrich-French \& McDonough, 2013). When the major focus of a player is to outperform others and win, she or he may be more inclined to engage in anti-social behaviors to achieve that goal (Bortoli, Messina, Zorba \& Robazza, 2012).

Research supports that shared moral norms influence the behavior of individual team members (Bortoli et al., 2012). When winning is measured through teamwork and adherence to values rather than just points scored, competition is no longer a divisive force. Rather, it drives youth to become the best versions of themselves. This is the foundation of the Latin American Street Soccer model.

\section{History}

It was estimated near the dawn of the Latin American Street Soccer movement there were about 100 million children and adolescents growing up on the streets of large cities worldwide (UNICEF, 1989). Two fifths (2/5) of the world's street youth were reported in South America, the majority being in Brazil (Barker \& Knaul, 1991 as cited in Campos et al., 1994). Though youth for decades informally tapped the positive qualities of free-play inherent in 
street soccer, it appears that overall the subgroup of youth who engaged in street soccer preceding the swell of the street soccer social movement were not typically those who were homeless and gang-involved based on the results of a 1992 study of the networks and daily activities of street youth in Brazil that provided some detailed insights into the lives of youth living on the streets (Campos et al., 1994). The study was conducted because of evolving research linking daily activities and associations with life-long developmental trajectories (Campos et al., 1994). Campos et al.'s (1994) study made a distinction between youth "on" the street who worked on the street but returned to their families to sleep and were home-based, and children "of" the street or street-based youth who were homeless. What the study found was that nearly two thirds (2/3) of the homeless, street-based youth belonged to a turma (group or gang) for support, companionship and protection (Campos et al. 1994, p. 323). The street-based youth were mostly involved in navigating the risks and temptations of street survival (Campos et.al., 1994). Per the Campos et al. study (1994), street soccer was not typically a reported element in the routines of street-based youth immediately predating the Street Soccer movement. However, in detailing their daily routines the average home-based youth described playing street soccer or cards daily in addition to working on the streets (Campos et.al., 1994).

In 1994, an Argentine organization, Defensores del Chaco, needed a more effective approach in dealing with gangaffiliated youth in the Buenos Aires outskirts of Moreno as system-imposed interventions were not working. The organization's early goal was to regain the dignity of having a safe place for its young people and entire neighborhood to gather (Fundacion Defensores del Chaco, 2017). They wanted to begin by initiating dialogue among people racked by violence (Movimiento de Futbol Callejero, 2017b). Without resources, about a dozen adolescents from the Club traversed a huge landfill where they installed a sign - Sports Club Chaco Defenders (Solmirano, 2011). These young people wanted to do more than play football; they wanted to change reality and claim a safe haven (Fundacion Defensores del Chaco, 2017; Solmirano, 2011). Hence, this modest, youth-driven initiative and others like it in the neighboring countries, helped launch the informal beginnings of the Latin American Street Soccer movement (Fundacion FUDE, 2021a,b; Fundacion Defensores del Chaco, 2017; Solmirano, 2011).

Though street soccer as an intervention for social change began as a neighborhood response, it quickly became an experience of collective construction expanding throughout the region. This grassroots effort spread among youth and communities in Latin America facing crises of growing proportions (Movimiento de Futbol Callejero, 2017b). Street soccer expanded from the neighborhood of Moreno (Argentina) and the outskirts of Lima, Villa Salvador (Peru), to communities of Cerro Navia in Santiago de Chile, the Paraguayan Chaco, and many other localities that discovered passion for the sport was creating civic engagement (Fundacion FUDE, 2017).

In 2008, members of Defensores del Chaco branched out into a new organization, FUDE (Fundacion Futbol para el Desarrollo /Futbol Development Foundation) to expand the local experience to a larger scale (Fundacion FUDE, 2017). They brought in experts to help in program expansion and model development. They further defined soccer as a tool to improve the quality of life in the most affected and excluded sectors of society. FUDE defends human rights using street soccer to drive the development of collective and transformative social practices (Fundacion FUDE, 2021a,c). FUDE, along with Defensores del Chaco and others, fueled the growth of the Street Soccer Movement.

El Movimiento de Futbol Callejero is an international coalition that promotes the use of street soccer as a vehicle for social change and peace building. Its application of street soccer as an agent of personal and social transformation differs according to need and context.

Though the organizations that make up the Street Soccer Movement share the common purpose of promoting community processes that improve living conditions, guarantee access to rights and promote more just and equal societies, they define autonomously their own initiatives, adapting them to the context and the community demand (Movimiento de Futbol Callejero, 2017c). In addition to young people, programs and public policies impacted, El Movimiento de Futbol Callejero sponsors the annual Latin American regional meetings of Street Soccer. It also facilitates information exchange and pursues best practices through the Latin American Congresses of Soccer and Development typically held annually pre-COVID-19 since 2010 (Movimiento de Futbol Callejero, 2017c).

The infectious nature of street soccer inspired numerous organizations worldwide to use the love of the sport to unite youth and communities in conflict. Many of these initiatives support youth leadership and well-being through street soccer. FIFA's (Fédération Internationale de Football Association) Football for Hope and UNESCO (United Nations Educational, Scientific and Cultural Organization) champion street soccer as a purposeful path to 
human rights (FIFA, 2017; UNESCO, 2017a). The market for street soccer programming that is faithful to its roots continues to increase. The need to engage isolated youth with complex needs and challenges is greater than ever, as according to UNESCO (2017b) there are up to 150 million street children in the world today.

Chased from home by violence, drug and alcohol abuse, the death of a parent, family breakdown, war, natural disaster or simply socio-economic collapse, many destitute children are forced to eke out a living on the streets, scavenging, begging, hawking in the slums and polluted cities of the developing world. (UNESCO, 2017a)

These numbers do not even come close to quantifying the needs of countless other young people facing diverse and formidable life challenges in their own family settings.

Street soccer programming is viewed as both providing a safe and fun space for youth engagement (Yoshitaka, 2015), as well as an opportunity bridge for personal development and social connectivity (Williams, 2013; Wilson, personal communication, 2018).

\section{Components}

The Latin-American Street Soccer's methodology differs from traditional soccer and other youth soccer initiatives in important ways. One of the few immutable rules in the game is that girls and boys play, preferably in equal numbers, together; this promotes gender equity and inclusion (Movimiento de Futbol Callejero, 2017a). No referees participate; the game is youth-directed. As captured in an UNESCO publication on point, this is to promote dialogue (Kuntz, 2006). The matches are divided into three distinct time periods (Movimiento de Futbol Callejero, 2017a). The values of respect, collaboration and solidarity guide each step of the process (IYAF Newsletter Special Edition, 2014; Movimiento de Futbol Callejero, 2017a; Youth Advocate Programs, Inc. 2021a).

The street soccer programming begins with integration activities. In step one, players sit together setting rules through consensus with a supportive mediator. The mediator is usually a mentor or youth leader who is trained to facilitate these discussions. The second step is the game itself. In the third step, the teams reconvene to discuss how the game developed on the field. Together the players explore whether the agreed upon rules were respected, as this influences point allocation. During the final phase, the players discuss the game, resolve disputes, and celebrate their shared victory. During all three periods, a mediator facilitates the dialogue exchange between the players, but does not intervene or regulate the game (Movimiento de Futbol Callejero, 2017a).

In a street soccer match under the Latin American methodology, it takes more than scoring goals to win. Victory may be achieved for points earned both by goals and by exhibiting the values of respect, collaboration and solidarity. The score reflects respect of the rules that the participants themselves agreed to prior to each encounter. This means that the team with the most goals does not necessarily win the match. It is through this methodology and its implementation, that the game becomes a strategy of social inclusion. The players' thoughtful deliberation and participation reclaims human values, promotes leadership development and generates a sense of community, belonging and solidarity (Movimiento de Futbol Callejero, 2017a). In this collaborative street soccer methodology, it is up to the players on both teams to decide the score once the game is over in a third halftime (Kuntz, 2006). The final score does not depend solely on goals scored, but also on things such as "clean" playing, comradeship and respect of the adversary (Kuntz, 2006).

The practice of mediation is the backbone of the methodology of street soccer (Fundacion FUDE, 2021d). It is a socio-constructive learning space that provides security, trust, self-regulation, and resolution (Movimiento de Futbol Callejero, 2017a). Mediation encourages dialogue and promotes participation (Movimiento de Futbol Callejero, 2017a). It is woven through all three stages of the game, bringing the process and the players together. Mediation is a process through which a neutral third party helps to facilitate decision-making. The neutrality of the mediator, specifically his or her impartial manner of facilitating dialogue without bias or judgment, is a critical component of the process. Through mediation, the players participate in collective reflection, decision-making and conflict resolution. 


\section{Street Soccer as a Positive Youth Development (PYD) Tool}

Concepts of Positive Youth Development are predicated on the idea that every young person has the potential for successful, healthy development, as all youths possess the capacity to grow and develop (Lerner, Lerner, et al., 2005). Research has tied sports to desired outcomes of positive development (Fraser-Thomas et al., 2005). Since street soccer is linked to improved health and physical fitness, youth leadership and civic engagement, it is championed as a Positive Youth Development (PYD) tool. Even though the frameworks describing the parameters of PYD vary, the focus of this paper is on several key personal and social assets positively influenced by engagement in sports.

\section{Personal/Developmental Assets}

Personal or developmental assets are important because they play three critical roles. They (1) protect against adverse or negative behaviors, such as substance use, (2) enhance a youth's likelihood to thrive, and (3) youths with increased developmental assets show greater resiliency in difficult situations (Fraser-Thomas et al. 2005). Luthar, Cicchetti and Becker (2000) define resilience as, "a dynamic process encompassing adaptation within the context of significant adversity" (p. 543). This paper looks at well-being, fun, hope, self-esteem, healthy lifestyles and respect.

Wellbeing. Physical activity is a useful foundation for PYD because, if it is set up appropriately, it can promote multiple components of well-being of at-risk groups (Ullrich-French \& McDonough, 2013). In discussing the complex concept of well-being in youth, social, emotional and relational aspects are often prominently featured (Cahill, 2015). Subjective wellbeing, or happiness, has long been considered core to optimal youth development (Park, 2004). There is research over the years supporting a relationship between exercise and happiness (Cheon, 2021). Developing a holistic approach to youth sports programming is especially important in promoting the wellbeing of youth participants.

Fun. A key ingredient of PYD revolves around fun. Studies highlight the importance of "creating a safe, comfortable and fun space for inspirational, meaningful youth engagement" (Yoshitaka, 2015). Negative impacts associated with youth participation in sports seem to be associated with taking the play out of the game. Smoll, Cumming and Smith (2011) scold society for the "professionalization" of youth sports (p.14). They conclude that most of the negative consequences of youth sports occur when a professional, highly competitive model is imposed on "what should be a recreational and educational experience for the youngsters... When excessive emphasis is placed on winning, it is easy to lose sight of the needs and interests of the young athlete" (Smoll et al. 2011, p. 14).

The basic right of the young athlete to have fun participating should not be neglected. One of the quickest ways to reduce fun is for adults to begin treating children as if they were professional athletes. Coaches and parents alike need to keep in mind that young athletes are not miniature adults. They are children, and they have the right to play as children. Youth sports are first and foremost a play activity, and youngsters deserve to enjoy sports in their own way. (Smoll et al. p. 15)

Research has supported the importance of ensuring that youth have enjoyable, positive immediate experiences in sport, and that accumulated positive experiences result, over time, in lasting effects on athletes' development ( Vierimaa, Turnnidge, Bruner \& Côté, J., 2017). Fun is what catapults the success of street soccer. It provides a stress release from the inevitable challenges of adolescence across cultural divides and is an especially important outlet and catalyst for youth living on the streets facing compounded challenges. The only ingredients required for street soccer are a ball and enthusiasm. "In Paso del Rey, as in most places in South America, throwing a soccer ball and letting it roll on the ground will get children rushing from all directions and ready to kick it..." (Kuntz, 2006, NP).

Hope. The fun of free play in soccer breeds hope for individual youth as well as communities (Camp \& Gray, 2016). "Hope is commonly regarded as the feeling that what is desired is also possible" (Obayuwana \& Carter, 1982 , p. 229). Positive sports involvement among youth is linked to increased developmental assets (FraserThomas et al. 2005). Youth who demonstrate more developmental assets, such as optimism regarding future 
happiness and success, are more likely to thrive (Fraser-Thomas et al. 2005). "Hopeful expectations for the future have been shown to play an important role in the positive development of youth, including youth contributions to society" (Callina, Johnson, Buckingham \& Lerner, 2014).

Lisa Solmirano, Coordinator at the 2014 Sao Paolo, Brazil Street Soccer World Cup was able to successfully portray hope in the below words in her description of the World Cup.

The international media coverage highlighted the daily struggles of these young people and their triumphs. Since the event ended, participants have communicated an outpouring of joy, hope and new dreams to achieve...perhaps this is the greatest victory: to encourage the youth to keep dreaming and to keep fighting to achieve it. (IYAF, 2014; also see Solmirano, 2011).

Self-esteem. Self-esteem presents researchers with complex assessment issues. Higher levels of self-esteem among youth are generally associated with greater likelihood to thrive. Positive outcomes include lower substance use, higher grades and greater resistance to peer pressure (Zimmerman, Copeland, Shope \& Dielman, 1997). However, self-esteem also presents certain PYD programming challenges. Individuals are more likely to gravitate to settings that provide opportunities to enhance self-esteem in relevant domains (Guerra \& Bradshaw 2008). Therefore, participation in sport programs may be especially rewarding to someone with athletic ability, thereby increasing his or her levels of self-esteem. Whereas, someone lacking natural athletic ability and self-esteem in that domain may be less inclined to participate in PYD programs with a strong physical activities' component.

Ullrich-French \& McDonough (2013) studied long term participation in physical-based positive youth development programs for low-income youth. Self-worth seemed to be a variable influencing continued program participation. Research suggests that more emphasis be placed on cooperation rather than competition in PYD programs with a physical context to downplay attention on individuals and improve inclusion and positive experiences (UllrichFrench \& McDonough, 2013). These recommendations dovetail perfectly with the Latin American street soccer programming that focuses on collaboration and does not contain the competitive and performance-based challenges of other sport programs.

Healthy lifestyles. There is voluminous literature on the health benefits of physical activities and exercise, particularly as pertaining to youth. The World Health Organization (2018) finds that the appropriate practice of physical activity assists young people with developing healthy musculoskeletal tissues, healthy cardiovascular system, and neuromuscular awareness (coordination), and maintaining a healthy body weight.

Physical activity has also been associated with psychological benefits in young people by improving their control over symptoms of anxiety and depression. Similarly, participation in physical activity can assist in the social development of young people by providing opportunities for self-expression, building self-confidence, social interaction and integration. (World Health Organization, 2018.)

Managing childhood obesity concerns can have life-long implications. Studies find that frequent participation in sports after school hours in adolescence is associated with a high level of physical activity in adulthood (Tammelin, Näyhä, Hills \& Järvelin, 2003). There is also research finding overweight youth are less likely to return to sports programs (Ullrich -French \& McDonough, 2013). This should be explored further to ensure youth, who may benefit from physical activity the most, feel comfortable participating. An advantage of the street soccer methodology is that it does not employ a competitive ambiance of comparison; rather it is value-focused and team-centered. This encourages the demonstration of respect, collaboration and solidarity among team members, which should create a more desirable environment for athletically challenged participants.

Respect. Respect is a core value of the Latin American borne street soccer methodology. Youth participating in the street soccer programming cooperatively establish a framework of respect within a self-regulated space (Movimiento de Futbol Callejero, 2017b). Playing by the rules cultivates respect among teammates and creates positive role models (Jiménez, 2006). Respectful communication, particularly within the expression of disagreement, is considered a critical building block of good character development (Battistich, 2008). 


\section{Skills}

Skills associated with street soccer cross a continuum of domains. For purposes of this paper, emotion management/self-regulation, leadership and conflict resolution are highlighted.

Emotion management. There is a need for continued research into the different paths to positive youth development through sport (Fraser-Thomas, et al., 2005). Gano-Overway, et al. (2009) explore emotion management and self-regulation as among the benefits of sports participation. It is difficult to establish direct linkages given the number of intervening variables. There is, however, longstanding evidence that supports the role of caring relationships in positive youth development (US Department of Health and Human Services, 2014). The role of caring adults and their impact on a youth's development of emotion management transplants naturally within the sports context.

[I]t is the perceived quality of interpersonal relationships between adults and youths within the caring climate that functions as a pathway to influence youths' regulatory skills to control emotions and empathy and subsequently to optimize prosocial behavior while simultaneously curtailing antisocial behavior. Therefore, sport leaders are potentially able to structure the environment to foster caring through modeling, creating teachable moments, communicating the importance of caring, and establishing a strong social norm that emphasizes caring for each other. (Gano-Overway, et al., 2009)

In many of the street soccer programs, participating youths are involved, or at risk of involvement, with the juvenile justice system (Youth Advocate Programs, 2021a,b). Anger can trigger anti-social behavior (Lochman, Barry, \& Pardini, 2003). Youth participating in YAP's street soccer-based skill programming are often youthful offenders facing challenges managing their emotions. Jason Wilson, a YAP street soccer trainer, champions the benefits of the Latin American street soccer programming among youth populations with complex needs.

A freestanding workshop on emotion or anger management or emotional regulation is not as effective as street soccer programming where positive sportsmanship and pro-social skill building become integral components that are practiced, not preached. Caring coaches, including young people from the community with prior involvement with systems themselves, model critical life skills and connect with the players. Through this program, players learn how to regulate their own behavior without the need for referees. (Jason Wilson, personal communication, 2018)

Leadership. Leadership is one of the primary skills targeted in street soccer programming. Leadership is prominently noted under the listed objectives of the FUDE street soccer approach, noting the methodology encourage the emergence of youth leaders by supporting their formation and the development of their life projects (Fundacion FUDE, 2021a; Movimiento de Futbol Callejero, 2017a). Through empowering youth to direct the game through collaborative decision-making, all participants are afforded leadership opportunities.

Conflict resolution. Conflict resolution is one of several posited PYD benefits of mainstream sports participation, even though typically absent from SBYD programs are the recognition of and specific strategies for helping youth to address tensions and conflicts that arise in their lives (Hemphill, et al., 2018). However, in the Latin American street soccer methodology, conflict resolution takes center stage (Fundacion FUDE, 2021d). Throughout all steps of the street soccer experience, mediation brings the players together (Fundacion FUDE, 2021d; Movimiento de Futbol Callejero (2017a).

Mediation is a process in which a third party helps disputants communicate with each other about how to best deal with a conflict (Mayer, 2012). Mediation within the street soccer context is a purely facilitative conflict management process. "[Mediation] helps people understand and accept differences as being normal" (Moore, 2014, p. 22). The mediator sets a positive tone and ensures all voices are heard; the mediator does not impose a solution (Mayer, 2012). The street soccer mediator models effective peace-building skills and by doing so helps the parties become more effective conflict managers in the game and beyond. And through utilizing a nonjudgmental, facilitative approach, the street soccer mediator ensures that the critical premise of self-determination, the will of the players, is respected. The players are empowered and united through participating in a consensus-building, decision-making process. This relational approach, that includes the integration of mediation and practical conflict 
management skill building, also mirrors characteristics identified in key research on the utilization of restorative practices within the sports context (Hemphill, et al., 2018).

\section{Social Assets}

The cultivation of social assets positions youth with challenging backgrounds to succeed better. The categorization of these assets depends upon which PYD framework is applied. For purposes of this paper, the focus is on group cohesion, family engagement, community connectivity and inclusivity.

Group cohesion. A study of the role of enjoyment and motivation climate as related to the personal development of team involved athletes found that five variables significantly predicted personal and social skills (MacDonald et al., 2011). The strongest predictor was affiliations with peers. This suggests that creating opportunities for positive peer interaction in the sport domain is beneficial for the development of personal and social skills (MacDonald et al., 2011). In a study of street soccer program participation among young people with psychosis, all participants commented on the positive social environment (Williams, Lloyd, King \& Paterson, 2013, p. 610). They identified "feeling welcomed and encouraged in the group environment as a key factor in deciding to continue" to participate in the program (Williams, et al., 2013, p. 610).

Teamwork, within teams and between teams, drives the Latin American street soccer methodology, from the first facilitated group circle discussion when the players set the rules, to the final mediation session when they reflect upon their embodiment of these values. Its emphasis on camaraderie versus competition dispels anxiety often associated with sports involvement. While emphasizing the "light-hearted," "open" street soccer environment, participating youth also identified the structure of the game as facilitating their ability to socialize (Williams et al., 2013, pps. 608-609).

Family engagement. There are decades of research supporting the important role of family and caregiver influence on positive youth development (Catalano, Berglund, Ryan, Lonczak \& Hawkins, 2004). There is significant research on the influence of sports on the development of youth. However, the family context in the research of PYD and sports is less explored. A study published in 2017 "examined the role and influence of families in a sportbased life skills program targeting positive youth development outcomes among an underserved youth population" (Hodge, Kanters, Forneris, Bocarro \& Sayre-McCord, 2017, p. 34). Hodge et al. (2017, p. 34) collected data using semi-structured interviews of youth and parents, finding "themes emerging from the data suggested the sportbased life skills program and participants' families were reciprocally influential and that this may have shaped opportunities for PYD outcomes."

Parents and youth perceived changes in behaviors (specifically, increased competencies) related to the life skills taught in the program, and these changes persisted after the program ended. Family presence and family involvement supported the acquisition and application of life skills and youth participation in the program created opportunities for bonding and reinforcement and recognition of positive changes within families. (Hodge et al. 2017, p. 34-35)

Latin American street soccer methodology is not about how to play soccer. It is about how to live life. With its emphasis on the core values of respect, collaboration and solidarity, and its integration of mediation and problem solving weaved throughout, it is a life skills program which includes sports rather than vice versa. Family engagement is an integral part of the street soccer programming as implemented by various NGOs and nonprofit organizations including Youth Advocate Programs (YAP). This coincides with the efforts of many NGOs to champion integrative services that expand formal and informal supports which include family, friends and community members.

Community connectivity and give-back. Community connections help reinforce life skills and provide support sources that are often lacking for youth with complex challenges. "If young people have mutually beneficial relations with the people and institutions of their social world, they will be on the way to a hopeful future marked by positive contributions to self, family, community, and civil society" (Lerner, Almerigi, Theokas \& Lerner, 2005). In mindful integration of street soccer programming, community partners are often recruited to serve a multitude of roles. Youth Advocate Programs' US based street soccer programs partner with local business and civic leaders to obtain field space, healthy meals and snacks, and uniforms and equipment. Community 
members serve as youth mentors. In one Pennsylvania community, YAP is exploring good faith and civic engagement through police and youth street soccer partnerships. Research on the police funded Kickz Social Inclusion program that at one time served over a hundred Great Britain programs showed marked reduction in criminal activities in impacted neighborhoods (Tysoe, 2014). These social inclusion programs improved youth and police relationships, drew young people away from negative social activities, and reduced crime by creating safer communities through positive development of youth (Tysoe, 2014).

Street soccer also provides creative opportunities for community give-back on the part of participating youth and families. Contribution is recognized as an important PYD component (Sherrod, 2007). Such civic engagement emphasizes "the important role that youth can and should play as participants and as agents of change in building the asset-promoting qualities of communities" and "the reciprocal interactions between building individual, community and societal assets" (Sherrod, 2007).

A UK study examined volunteering in the capacity of youth sport in developing social capital (Kay \& Bradbury, 2009). It focused on "the ability of a structured sports volunteering program to equip young people with skills for effective volunteering and provide opportunities for 'social connectedness' through sports volunteer placements" (Kay \& Bradbury, 2009, p. 2). Social capital is a widely debated concept among theorists and policymakers. However, the Kay and Bradbury study "yielded sufficient evidence to show for many young people, sports volunteering can work as a mechanism for fostering human capital and encourage the practical and intellectual connectedness which underpins the idea of social capital" (2009, p. 28). Sports researchers should now be able to be less "tentative in some of their claims about whether sport can yield social benefits: it can" (Kay \& Bradbury, 2009, p. 28). Though research is needed in this area of social capital, particularly as the permanence of these impacts is yet to be established (Kay \& Bradbury, 2009), the importance of youth give-back opportunities within the PYD construct is firmly grounded.

Community give-back is key to YAP's street soccer programming approach. Community service across a wide and creative spectrum provides a sense of community belonging and connectivity - the benefits of which are especially significant among socially isolated populations (Petrilla, Silva, Huggins, McNamara \& Sylk, 2020; Silva, Petrilla, Matteson, Mannion \& Huggins, 2019; US Department of Health and Human Services, 2014). It also provides the community with a different lens through which to view these youth volunteers, rather than just as system-involved young people.

Inclusivity/gender equity. Gender equity is a concern in sports as it is in life across all domains. "Although the field of sport has made significant strides to ameliorate past discrimination and prejudice toward female athletes, many of these efforts only managed to change impact on the surface level" (Cohen, Melton \& Peachey, 2014, p. 222). A separate and unequal description seems to best depict the evolution of female sports.

The Latin American street soccer methodology champions inclusion and gender equality. One of the few imposed rules in the Latin American street soccer methodology is the mandatory participation of girls on the team. The YAP street soccer approach includes equal numbers of males and females playing on the field at the same time. Co-ed teams cultivate a sense of fairness and mutual respect among the players.

On a global scale, the United Nations (UN) is utilizing sport to eliminate gender disparity in all levels of education (Cohen, et al. 2014).

As part of its Millennium Development Goals, the UN is using sport as a mechanism to address social justice and equality across an array of issues, including gender equality. However, sport will not become a vehicle for social equality if sport leaders use the same gender paradigm as they have before. Instead, they must conceive of new ways males and females can enjoy sport together. (Cohen et al., 2014 p. 223)

The Latin American street soccer methodology embodies this paradigm shift through unequivocal inclusion in principle and practice.

\section{YAP Street Soccer Experience}

Youth Advocate Programs, Inc. is a US based nonprofit organization committed to setting a worldwide standard in promoting and providing cost-effective in-home and community-based care opportunities for disenfranchised 
populations who are otherwise deleteriously detained or institutionalized (YAP International Programs Strategic Plan, 2016; Youth Advocate Programs, Inc., 2021c). YAP supports, serves, organizes and empowers the young people, adults and families who are living in marginalized situations in the US and, increasingly, abroad (Youth Advocate Programs, Inc., 2021a). YAP uses creative, family and community-centered programming to engage youth and families for whom traditional, system-imposed interventions fail (Silva, et al., 2019; Youth Advocate Programs, Inc., 2021c).

YAP embraces the Latin American street soccer programming as an effective PYD tool, joining the Latin American street soccer movement in 2014. YAP partnered with the International Youth Advocacy Federation, a multinational consortium dedicated to helping youth and families worldwide who lack critical economic and social supports to recruit teams of international participants for the 2014 Street Soccer World Cup in Brazil. A US YAP delegation of youth representatives, consisting of program clients and alumni, participated directly in the games. YAP-associated teams of participants at the Street Soccer World Cup in Sao Paulo included: 1.) Team US with delegates from YAP and the International Youth Advocacy Federation member "Humanity Helping Sudan Project;" 2.) Team Sierra Leone YAP; and 3.) Team Ghana - a collaboration of two IYAF, International Youth Advocacy Federation, member organizations (Youth Advocate Programs, Inc., 2021d).

The World Cup brought youth from around the world together to celebrate the values of sportsmanship and teamwork. Youth delegations from over 20 countries participated in the 2014 Street Soccer World Cup Event (Futebol de Rua Brasil) in San Paolo. The Street Soccer World Cup showcased more than athletic prowess and agile footwork. On the streets of San Paolo, young people from diverse cultures interacted together as comrades rather than combatants (Fundacion FUDE, 2021e). They were not youth of means. They were typically youth from economically impoverished neighborhoods whose attendance was funded by companies and foundations. The two-week long street futbol tournament was devoted to social inclusion, human rights, leadership development, team building and peaceful conflict resolution.

A youth participant and US delegate, Isabel, shared the below recollection of her experience in the Street Soccer World Cup. It reflects the personal and social assets attributed to sports, and specifically street soccer, discussed earlier.

The more games we played, the more I began to realize that the real purpose of the tournament had nothing to do with soccer...Street Soccer helped me realize that sports are just a medium. On the field, individuals decide what aspects of themselves they want to bring to the field. Something novel I learned: one doesn't have to bring animosity, and animosity does not drive competition. This was a weird concept to grasp for me, but the tournament continually drove the idea home. There was always a lot of joy on our fields in Sao Paulo, and it was never a result of the score. (Youth Advocate Programs, Inc., 2015)

A year later, YAP youth participated in the 2015 Nelsa Curbelo Street Soccer America Cup in Argentina. The YAP Team represented a diverse cross-section of the type of youth to whom YAP provides services. The support of the US Embassy in Buenos Aires enabled Brazil alumnae to return to the next Copa as mentors. The Nelsa Curbelo Street Soccer America Cup is not just a sporting event. It is fundamentally a meeting between cultures and projects from different countries of the continent (Fundacion FUDE, 2021f). The two tournaments in Brazil and Argentina embraced street football as a central element of their programs of inclusion, youth development, prevention of violence and promotion of dialogue.

Shortly after participating in the Nelsa Curbelo Street Soccer America Cup, YAP launched its first pilot street soccer program in Orange County, New York in November 2015. That same month, with the support of the US Embassy in Buenos Aires, Fundacion FUDE staff partnered with YAP to provide street soccer trainings in New York and Harrisburg to YAP staff from around the US, and to partner organizations in Sweden and Ireland. YAP staff then traveled to Buenos Aires for immersion learning with their FUDE hosts.

In March 2016, YAP staff visited YAP Ireland to train staff and youth on the Street Soccer methodology. Since the training, YAP Ireland began to integrate mediation and peace building through soccer into their programming (Youth Advocate Programmes, Ireland, 2021). "Through continued collaboration, YAP Ireland now has the tools to move the street soccer programme forward in Ireland and possesses the passion and capabilities to transform lives, change biographies and in the process, make the world a little brighter for all" (Youth Advocate Programmes, Ireland, 2021). Also in 2016, a delegation from FUDE in Argentina participated in the 40th anniversary of YAP in 
Harrisburg, Pennsylvania which included training workshops and a demonstration street soccer game. Representatives from YAP's sister agency in Guatemala, "Siembra Bien," represented YAP at a FUDE-organized street soccer tournament in Buenos Aires in October 2016. That same year, YAP and Lebanon Valley College partnered for a street soccer training program and tournament in which Guatemalan delegates participated. In 2018 YAP's sister agency in Guatemala, Siembra Bien, took a team of youth living in street situations to a "Homeless World Cup" in Mexico, winning a second-place trophy (Homeless World Cup Foundation, 2018a,b).

Pre-COVID, Orange County YAP in New York ran two soccer programs for local youth ages 8-12 and 13-17. This soccer program (pre-pandemic) served over 100 youth and families annually; programming ran every week throughout the year. YAP further cultivated interest in the Latin American street soccer programming across other states with existing YAP support services for youth and families involved in the juvenile justice, child welfare or other systems of care. Its collaborative street soccer initiative in Denver is illustrative of the critical role and benefits of community partnering. In 2019, community partners supported an elementary school partnership that engaged youth facing behavioral, socio-economic and family challenges. Though the pandemic paused progress on this front both nationally, as in Denver, and internationally, planning is underway for expansion of YAP street soccer programs as the world comes back together, particularly in safer outdoor spaces.

In addition to expanding its soccer programming as a stand-alone or complementary intervention for its diverse youth service population, YAP is seeking funding to develop its national street soccer training institute in New York. Efforts are also underway to ensure the sensitivity and responsiveness of the implementation of its soccer programming across cultures. Ensuring fidelity to the Latin American value-based, mediation-centered model is a YAP priority. Moving forward, YAP seeks to expound on the mediation component of the model through integrating more interactive conflict management exercises within the training curricula and program implementation. YAP further hopes to create greater leadership opportunities for its soccer alumni as programming expands. Through its extensive outcome tracking system, YAP will contribute to the growing body of research on PYD through sports (specifically street soccer) participation.

Finally, YAP also looks to expand the methodology's application to innovative substantive areas, including as a supplementary intervention with youth who are gang involved or at-risk of gang involvement with the hope of cultivating conflict management skills aimed at preventing and interrupting cycles of individual and community violence (Youth Advocate Programs, Inc., 2021b). Street soccer is as much a societal asset as it is a positive youth development tool. Within the framework of the implementation of public policies that seek to improve urban living conditions in marginalized neighborhoods, FUDE has been developing an inclusive soccer program with the city government of Buenos Aires since 2012 (Fundacion FUDE, 2021g). Street Soccer was also part of an International Day of Sport for Development and Peace celebration in April 2021 that featured a simultaneous YAP Global Youth Voices initiative in Guatemala City, Guatemala and Trenton, New Jersey. Young social mediators who work with Siembra Bien virtually co-hosted this event with members of a New Jersey based YAP community partner organization (Youth Advocate Programs, Inc., 2021e). These examples illustrate the potential holistic and reciprocal benefits of the street soccer movement and its rich potential as a youth empowerment platform, elevating the voices of evolving young leaders worldwide (Fundacion FUDE, 2021c).

As noted by Taylor and Smith in their research on developing youth policies, "integration of children's agency, rights, and well-being provides a conceptual framework for positioning children as participating subjects, knowers, and social actors, rather than as the passive objects of socialization" (2015). This brings us full circle, back to the youth who claimed and transformed a landfill site in Argentina into a positive space for hope and growth (Movimiento de Futbol Callejero, 2017b; Solmirano, 2011). Constructively channeling the powerful, relational dynamics and opportunities between communities and their members is a cornerstone of the street soccer movement. On all fronts, through its national and international partnerships including its membership within Movimiento de Futbol Callejero, YAP will continue to pursue creative and collaborative efforts to promote the Latin American street soccer methodology as a tool for positive youth development as well as social transformation.

\section{Conclusion}

Over 150 million youth are estimated to be living on the streets (UNESCO, 2017a). Countless others are living within lower income and limited resource households with numerous unmet needs and complex challenges. Holistic Latin American street soccer programming, with its modest youth-directed beginnings, is emerging as a sustainable and effective positive youth development tool. The model's appeal is especially apparent in the global south where it has strong roots. 
It is through fidelity to its integrative methodology that the game becomes a strategy of social inclusion. Girls and boys play together as equals - promoting inclusivity and gender equity. The whole of the experience is even greater than its three powerful components. The methodology empowers participants to use consensus building through mediation to establish rules, regulate their own interactions and reframe the concept of winning. Players' adherence to mutually agreed upon values informs their deliberations in choosing the winning team though all players celebrate a shared victory of the core values of respect, collaboration and solidarity (Youth Advocate Programs, Inc., 2021a,b).

There is extensive literature on the benefits, and challenges, of youth participation in sports as an effective youth development mechanism. Research supports the benefits of holistic sport programs that are: youth-directed (Snow, 2011); cooperative rather than competitive (Ullrich-French \& McDonough, 2013); and family oriented (Hodge et al. 2017). More recently, research has also explored the potential of "how restorative practice can be utilized in a sport context" (Hemphill, et al., 2018, p. 76). The Latin American street soccer model embraces all these concepts and components.

Youth Advocate Programs has an extensive history and promising future of working with organizations nationally and abroad to help expand the opportunities afforded by high fidelity Latin American street soccer programming. Diana Matteson, YAP's International Development Director, leads YAP's efforts in assisting interested parties explore new substantive areas of potential application, expand into other geographic venues, and cultivate creative programming that champions the values of the Latin American street soccer methodology in empowering youth. It is a powerful positive youth development tool that builds resilience and promotes youth, family and community transformation.

\section{References}

Anderson-Butcher, D. (2019). Youth sport as a vehicle for social development. Kinesiology Review, 8(3), $180-187$.

Bailey, R. (2006). Physical education and sport in schools: A review of benefits and outcomes. Journal of school health, 76(8), 397-401. https://doi.org/10.1111/j.1746-1561.2006.00132.x

Battistich, V. A. (2008). Voices: A practitioner's perspective: Character education, prevention, and positive youth development. Journal of Research in Character Education, 6(2), 81. Retrieved from The Relationships Between Character Education and the Prevention of Problem Behaviors: A Position Statement (hhs.gov)

Bortoli, L., Messina, G., Zorba, M., \& Robazza, C. (2012). Contextual and individual influences on antisocial behavior and psychosocial states of youth soccer players. Psychology of Sport and Exercise, 13(4), 397-406. Retrieved from Contextual and individual influences on antisocial behaviour and psychobiosocial states of youth soccer players (researchgate.net)

Cahill, H. (2015). Approaches to understanding youth well-being. Handbook of children and youth studies, 95-113.

Callina, K. S., Johnson, S. K., Buckingham, M. H., \& Lerner, R. M. (2014). Hope in context: Developmental profiles of trust, hopeful future expectations, and civic engagement across adolescence. Journal of youth and adolescence, 43(6), 869-883.

Camp, B., \& Gray, J. (2016). Providing Positive Experiences in Youth Sport: Successes, Failures, and Creative Practices in Youth Soccer. Illuminare: A Student Journal in Recreation, Parks, and Tourism Studies, 14.

Campos, R., Raffaelli, M., Ude, W., Greco, M., Ruff, A., Rolf, J., ... \& Street Youth Study Group. (1994). Social networks and daily activities of street youth in Belo Horizonte, Brazil. Child development, 319-330. Retrieved from Social Networks and Daily Activities of Street Youth in Belo Horizonte, Brazil (unl.edu)

Catalano, R. F., Berglund, M. L., Ryan, J. A., Lonczak, H. S., \& Hawkins, J. D. (2004). Positive youth development in the United States: Research findings on evaluations of positive youth development programs. The annals of the American academy of political and social science, 591(1), 98-124. Retrieved from Positive-Youth-Developmentin-the-United-States-Research-Findings-on-Evaluations-of-Positive-Youth-Development-Programs.pdf (researchgate.net)

Cheon, H. (2021). The Structural Relationship between Exercise Frequency, Social Health, and Happiness in Adolescents. Sustainability, 13(3), 1050.

Cohen, A., Melton, E. N., \& Peachey, J. W. (2014). Investigating a coed sport's ability to encourage inclusion and equality. Journal of Sport Management, 28(2), 220-235. 
FIFA, Football for Hope (2017). Retrieved from untitled (efdn.org)

Fraser-Thomas, J. L., Côté, J., \& Deakin, J. (2005). Youth sport programs: An avenue to foster positive youth development. Physical Education \& Sport Pedagogy, 10(1), 19-40. https://doi.org/10.1080/1740898042000334890

Fundacion Defensores del Chaco. (2017). Retrieved from History| Defensores del Chaco Foundation

Fundacion FUDE. (2017). Retrieved from http://www.fundacionfude.org.ar/quienes-somos/historia/

Fundacion FUDE. (2021a) About Us. Retrieved from http://www.fundacionfude.org.ar/quienes-somos/

Fundacion FUDE. (2021b) What We Do>Street Soccer. Retrieved from http://www.fundacionfude.org.ar/futbolcallejero/

Fundacion FUDE. (2021c). What We Do>Football for Social Opportunity. Retrieved http://www.fundacionfude.org.ar/

Fundacion FUDE. (2021d). What We Do>Regional School of Mediators. Retrieved from http://www.fundacionfude.org.ar/escuela-regional-de-mediadores-

Fundacion FUDE. (2021e). Mundial Futbol Callejero Brasil 2014. Retrieved from http://www.fundacionfude.org.ar/multimedia

Fundacion FUDE. (2021f).Copa America de Futbol Callejero-Buenos Aires 2014. Retrieved from MULTIMEDIA - Fude Foundation (fundacionfude.org.ar)

Fundacion FUDE. (2021g). What We Do>Football and Inclusive Habitat. Retrieved from http://www.fundacionfude.org.ar/futbol-y-habitat-inclusivo/

Gano-Overway, L. A., Newton, M., Magyar, T. M., Fry, M. D., Kim, M. S., \& Guivernau, M. R. (2009). Influence of caring youth sport contexts on efficacy-related beliefs and social behaviors. Developmental psychology, 45(2), 329. https://doi.org/10.1037/a0014067

Guerra, N. G., \& Bradshaw, C. P. (2008). Linking the prevention of problem behaviors and positive youth development: Core competencies for positive youth development and risk prevention. New directions for child and adolescent development, 2008(122), 1-17. Retrieved from https://pdfs.semanticscholar.org/f0b1/77307ad801a4843ac6be6f9613b7af0e19fc.pdf

Hemphill, M. A., Janke, E. M., Gordon, B., \& Farrar, H. (2018). Restorative youth sports: An applied model for resolving conflicts and building positive relationships. Journal of Youth Development, 13(3), 76-96.

Hodge, C. J., Kanters, M. A., Forneris, T., Bocarro, J. N., \& Sayre-McCord, R. (2017). A Family Thing: Positive Youth Development Outcomes of a Sport-Based Life Skills Program. Journal of Park \& Recreation Administration, 35(1). https://doi.org/10.18666/JPRA-2017-v35-I1-6840

Holt, N. L., Neely, K. C., Slater, L. G., Camiré, M., Côté, J., Fraser-Thomas, J., ... \& Tamminen, K. A. (2017). A grounded theory of positive youth development through sport based on results from a qualitative metastudy. International review of sport and exercise psychology, 10(1), 1-49.

Homeless World Cup Foundation (2018). Retrieved from "We can become more than just a young person living on the street" - Homeless World Cup

Homeless World Cup Foundation (2018). Retrieved from https://homelessworldcup.org/mexico-2018-finalstandings/

IYAF, International Youth Advocacy Federation, Special Edition Newsletter. (2014).

Jiménez, J. (2006). Street football in Paso del rey/Iglesia Kuntz, UNESCO Courier, September 2006. Retrieved from http://unesdoc.unesco.org/images/0019/001915/191579e.pdf

Kay, T., \& Bradbury, S. (2009). Youth sport volunteering: developing social capital? Sport, Education and Society, 14(1), 121-140. https://doi.org/10.1080/13573320802615288

Kuntz, I. L. (2006). Street football in Paso del rey, UNESCO Courier, September 2006.

Retrieved from http://unesdoc.unesco.org/images/0019/001915/191579e.pdf

Lerner, R. M., Almerigi, J. B., Theokas, C., \& Lerner, J. V. (2005). Positive youth development a view of the issues. The journal of early adolescence, 25(1), 10-16. 
Lerner, R. M., Lerner, J. V., Almerigi, J. B., Theokas, C., Phelps, E., Gestsdottir, S. \& Smith, L. M. (2005). Positive youth development, participation in community youth development programs, and community contributions of fifthgrade adolescents: Findings from the first wave of the 4-H study of positive youth development. The Journal of Early Adolescence, 25(1), 17-71. Retrieved from http://journals.sagepub.com/doi/abs/10.1177/0272431604272461

Lochman, J. E., Barry, T. D., \& Pardini, D. A. (2003). Anger control training for aggressive youth. Evidence-based psychotherapies for children and adolescents, 2, 227-242. Retrieved from https://178516c1-a-62cb3a1a-ssites.googlegroups.com/site/victoriaecosgrovephd/teaching/child-adolescent-and-family-psychotherapy/week8-5-19-2011/Lochman et al Ch 15.pdf?attachauth=ANoY7cr4XAAnMEdipHV82jz2u0IHO3jxs8U1mLRQa egkX91LbkFiMk9yKPvROmGApvsEa22Chhx9r9fMo1T9QPLpFpQV14OurwFusn5H5 -jQ2L7H5z7xulYVnIUjb65hBs3fdRI1rOeXTnExLXxKNoEuMYiDFC6WXGQLLPgFOCGwqF1bQ0V6phaDhfFbOTG P0v gSJnQHZfORJ6Ew5 BdNuNxdNkMURZbMI788as7 OUwlKbiNgPJdCsiozVtBrgcevAz5tBIhqJIJBonuGa-PwNLW-GoW027U9nJ3uaafaiV6o0KpvJSU5QymmDAYfd7hLGh-0j86aSZexB bE5PEFCrIGw\%3D\%3D\&attredirects=0

Luthar, S. S., Cicchetti, D., \& Becker, B. (2000). The Construct of Resilience: A Critical Evaluation and Guidelines for Future Work. Child Development, 71(3), 543-562. https://doi.org/10.1111/1467-8624.00164

MacDonald, D. J., Côté, J., Eys, M., \& Deakin, J. (2011). The role of enjoyment and motivational climate in relation to the personal development of team sport athletes. The Sport Psychologist, 25(1), 32-46. Retrieved from https://www.islandscholar.ca/islandora/object/ir\%3A1796/datastream/PDF/view

peach

Mayer, B. (2012). The dynamics of conflict: A guide to engagement and intervention. John Wiley \& Sons.

Moore, C. W. (2014). The mediation process: Practical strategies for resolving conflict. John Wiley \& Sons.

Movimiento de Futbol Callejero. (2017a). Retrieved from http://movimientodefutbolcallejero.org/futbolcallejero/metodologia/

Movimiento de Futbol Callejero. (2017b). Retrieved from http://movimientodefutbolcallejero.org/futbolcallejero/historia/

Movimiento de Futbol Callejero, (2017c). Retrieved from http://movimientodefutbolcallejero.org/futbolcallejero/contacto/

Obayuwana, A. O., \& Carter, A. L. (1982). The anatomy of hope. Journal of the National Medical Association, 74(3), 229.

Park, N. (2004). The role of subjective well-being in positive youth development. The Annals of the American Academy of Political and Social Science, 591(1), 25-39. https://dx.doi.org/10.1177/0002716203260078

Petrilla, C. M., Silva, D. J., Huggins, S. L., McNamara, R., \& Sylk, G. (2020). Journal of Applied Juvenile Justice Services. Retrieved from Microsoft Word - Healing Lives (Petrilla) KD.docx (npjs.org)

Sherrod, L. (2007). Civic engagement as an expression of positive youth development. Approaches to positive youth development, 1, 59-74.

Silva, D. J., Petrilla, C. M., Matteson, D., Mannion, S., \& Huggins, S. L. (2019). Increasing Resilience in Youth and Families: YAP's Wraparound Advocate Service Model. Child \& Youth Services, 1-32. https://doi.org/10.1080/0145935X.2019.1610870

Smoll, F. L., Cumming, S. P., \& Smith, R. E. (2011). Enhancing coach-parent relationships in youth sports: Increasing harmony and minimizing hassle. International Journal of Sports Science \& Coaching, 6(1), 13-26.

https://doi.org/10.1260/1747-9541.6.1.13

Snow, S. (2011). US youth soccer player development model.

Solmirano, L. (April, 2011). Sports and Inclusion, TED Conferences. http://www.fundacionfude.org.ar/multimedia/

Tammelin, T., Näyhä, S., Hills, A. P., \& Järvelin, M. R. (2003). Adolescent participation in sports and adult physical activity. American journal of preventive medicine, 24(1), 22-28. https://dx.doi.org/10.1016/S07493797(02)00575-5

Taylor, N., \& Smith, A. B. (2015). Thinking About Children: How Does It Influence Policy and Practice?. Handbook of Children and Youth Studies, 49. 
Tysoe, K. (2014). The positive impact of sport on youth.

Ullrich-French, S., \& McDonough, M. H. (2013). Correlates of long-term participation in a physical activity-based positive youth development program for low-income youth: Sustained involvement and psychosocial outcomes. Journal of adolescence, 36(2), 279-288. Retrieved from Correlates of long-term participation in a physical activity-based positive youth development program for low-income youth: Sustained involvement and psychosocial outcomes (wsu.edu)

UNESCO, United Nations Educational, Scientific and Cultural Organization (2017a). International Charter of Physical Education, Physical Activity and Sport.

UNESCO, United Nations Educational, Scientific and Cultural Organization (2017b). Social and Human Sciences: Street Children.

UNICEF (1989). UNICEF Annual Report:1989. Retrieved from https://www.unicef.org/about/history/files/unicef annual report 1989.pdf

US Department of Health and Human Services. (2008). US Department of Health and Human Services 2008 physical activity guidelines for Americans. Hyattsville, MD: Author, Washington, DC, 2008, 1-40.

US Department of Health and Human Services, (2014). "Protective Factors Approaches in Child Welfare," Child Welfare Information Gateway, February 2014. Retrieved from https://www.childwelfare.gov/pubPDFs/protective factors.pdf

Vierimaa, M., Turnnidge, J., Bruner, M., \& Côté, J. (2017). Just for the fun of it: Coaches' perceptions of an exemplary community youth sport program. Physical Education and Sport Pedagogy, 22(6), 603-617.

Williams, P., Lloyd, C., King, R., \& Paterson, M. (2013). Street Soccer programme participation: Experiences of young people with psychosis. International Journal of Therapy and Rehabilitation, 20(12), 606-611. Retrieved from https://doi.org/10.12968/ijtr.2013.20.12.606

World Health Organization. (2018). Global Strategy on Diet, Physical Activity and Health:

Physical Activity and Young People.

Yoshitaka, Iwasaki (2015). The role of youth engagement in positive youth development and

social justice youth development for high-risk, marginalised youth, International Journal of Adolescence and Youth, 21:3, 267-278, DOI: http://doi.org/10.1080/02673843.2015.1067893

Youth Advocate Programs, Inc. (2015). International Highlights 2013-2014, unpublished report.

Youth Advocate Programs, Inc. (2016). YAP's International Programs Strategic Plan. (20162020).

Youth Advocate Programs, Inc. (2021a). Street Soccer Fact Sheet. Retrieved from SS fact.pdf (yapinc.org)

Youth Advocate Programs, Inc. (2021b). Our Services> Innovation> Street Soccer. Retrieved from Innovation (yapinc.org)

Youth Advocate Programs, Inc. (2021c). What we do. Retrieved from What We Do (yapinc.org)

Youth Advocate Programs Inc. (2021d). YAP Youth Competes in Street Soccer World Cup Retrieved from YAP Youth Competes in Street Soccer World Cup - YAP News (yapinc.org)

Youth Advocate Programs, Inc. (2021e). Retrieved from Youth Raising Global Awareness of How Sports can Minimize Dangers Leading Kids to Seek Asylum in U.S. - Article Details (vapinc.org)

Youth Advocate Programmes Ireland. (2021) Retrieved from https://yapireland.ie/yap-street-soccer-event/

Zimmerman, M. A., Copeland, L. A., Shope, J. T., \& Dielman, T. E. (1997). A longitudinal study of self-esteem: Implications for adolescent development. Journal of youth and Adolescence, 26(2), 117-141. Retrieved from https://deepblue.lib.umich.edu/bitstream/handle/2027.42/45283/10964 2004 Article 423239.pdf?sequence =1\&isAllowed=y 